MATEC Web of Conferences 22,04015 (2015)

DOI: $10.1051 /$ matec conf/ 20152204015

(C) Owned by the authors, published by EDP Sciences, 2015

\title{
Application and Optimization of Biolog EcoPlates in Functional Diver- sity Studies of Soil Microbial Communities
}

\author{
Wenhuan $\mathrm{Xu}^{*}$ \& Zhiwei Ge \\ College of Biology and the Environment, Nanjing Forestry University, Nanjing, Jiangsu, China \\ Daya Ram Poudel \\ Department of Forest, Nepal
}

\begin{abstract}
The biological diversity contributes to many aspects of human well-being and ecosystem function, however, we have known very little about microbial diversity due to the limitations of appropriate methodology underneath it. The development of biotech have brought revolutionary progress in the study of microbial diversity in which Biolog required to pay a lot of attention due to its ability of reflecting the metabolic situation of living microbial communities and have used widely in the study of soil microbial communities. However, there are some controversies during its operation procedure and incubation process, handling large data during the analysis might have also caused trouble in the overall process. The approach based on uses of "absolute used" "INDIRECT" function in Excel could greatly optimize the data analysis, and the increase of principle components in Principle Component Analysis (PCA) were able to extract more information from original data. Besides, the method that through "Taylor" and "logic" transformation for original data before PCA analysis could achieve data analysis optimization. This paper have presented the applications and optimization of Biolog EcoPlates in studies of functional diversity of microbial communities, presented its inherent biases and prospects, provided some reference for the applications and popularization of Biolog EcoPlates for microbial study and finally, the results imply improving the knowledge of biotech in study of soil microbial functional diversity.
\end{abstract}

Keywords: Biolog Eco plates; microbial communities; functional diversity; PCA analysis;

\section{INTRODUCTION}

Biodiversity is significant to human, many studies [1-3] showed a close relationship between the biological diversity and the ecosystem stability. Lots of studies on flora and fauna diversity, however, we just have little known on microbial diversity due to the limitations of methodology [4]. In ecosystem, soil microorganisms play a role of decomposer and have irreplaceable place in energy flow and matter cycle, from which bacteria communities have the largest number and vital function [5-6]. Therefore learning the metabolic ability, utilization of carbon sources, genetic and functional diversity of soil bacterial communities is meaningful [7-8].

The development of biotech brought revolutionary progress in the studies of microbial diversity, which made us be able to learn microbial diversity by checking DNA sequence [9]. Although the method based microbial DNA is a more accurate way to acquire the information of diversity [10], yet in International Microbiology Congress 2014, some scholars claimed that Biolog technique based on living microorganism is a more practical way to show microbial function in ecosystem. This paper showed the applications of Biolog EcoPlates in functional diversity studies of microbial communities, presented its inherent biases and the way to optimize data analysis, provided

*Corresponding author:543964578@,qq.com the reference for the applications and popularization of Biolog EcoPlates and improving the applications of biotech in study of microbial ecology.

\section{BASIC PRINCIPLE AND CHARACTERISTICS OF BIOLOG ECOPLATES}

The basic principle of Biolog technique is to culture the microorganisms from the environment, and compare the metabolic fingerprint and specific pattern of color change on the plate with Biolog database to identify the microorganisms [11]. So far, 1449 bacterial and yeast species/taxa in the Biolog database. Different kinds of plates based on study objects, such as Biolog GN plates (Gram-negative bacteria), Biolog EcoPlates, Biolog FF plates (fungi), Biolog YT plates, SPF1, SPF2 et al, in which GN, Eco, were for bacterial communities. Although the plates are different, yet the basic principle of Biolog EcoPlates is the same with others, which is that metabolism of the substrate in particular wells results in formazan production, producing color change in the tetrazolium dye.

Three basic characteristics in Eco plates. First, there are 31 individual carbon sources which have ecological meaning in each core (Table1). Second, there are 3 repeats on a 96 well plate. A complete union includes 32 wells with 31 individual carbon sources plus one water control. Third, there is a large data in analysis. 


\section{MATEC Web of Conferences}

In the studies of soil ecology, at least 4 treatments with 4 repeats for each treatment, 16 samples in all. Each plate provides 93 numbers in each day, multiple 10 days, and 930 numbers for each plate.

Table 1. 31 Individual arbon substrates found in the Biolog ECO plates

\begin{tabular}{|c|c|c|}
\hline $\begin{array}{l}\text { Chemical } \\
\text { guild }\end{array}$ & Substrate & $\begin{array}{l}\text { Chemical } \\
\text { formula }\end{array}$ \\
\hline \multirow{2}{*}{$\begin{array}{l}\text { Amines/amide } \\
\mathrm{s}\end{array}$} & Phenylethylamine & $\mathrm{C}_{8} \mathrm{H}_{11} \mathrm{~N}$ \\
\hline & Putrescine & $\mathrm{C}_{4} \mathrm{H}_{12} \mathrm{~N}_{2}$ \\
\hline \multirow[t]{6}{*}{ Amino acids } & Glycyl-1-glutamic acid & $\mathrm{C}_{7} \mathrm{H}_{12} \mathrm{~N}_{2} \mathrm{O}_{5}$ \\
\hline & 1-Arginine & $\mathrm{C}_{6} \mathrm{H}_{14} \mathrm{~N}_{4} \mathrm{O}_{2}$ \\
\hline & 1-Asparagine & $\mathrm{C}_{4} \mathrm{H}_{8} \mathrm{~N}_{2} \mathrm{O}_{3}$ \\
\hline & 1-Phenylalanine & $\mathrm{C}_{9} \mathrm{H}_{11} \mathrm{NO}_{2}$ \\
\hline & 1-Serine & $\mathrm{C}_{3} \mathrm{H}_{7} \mathrm{NO}_{3}$ \\
\hline & 1-Threonine & $\mathrm{C}_{4} \mathrm{H}_{9} \mathrm{NO}_{3}$ \\
\hline \multirow[t]{7}{*}{ Carbohydrates } & $\alpha$-d-Lactose & $\mathrm{C}_{12} \mathrm{H}_{22} \mathrm{O}_{11}$ \\
\hline & $\beta$-Methyl-d-glucoside & $\mathrm{C}_{7} \mathrm{H}_{14} \mathrm{O}_{6}$ \\
\hline & d-Cellobiose & $\mathrm{C}_{12} \mathrm{H}_{22} \mathrm{O}_{11}$ \\
\hline & d-Mannitol & $\mathrm{C}_{6} \mathrm{H}_{14} \mathrm{O}_{6}$ \\
\hline & d-Xylose & $\mathrm{C}_{5} \mathrm{H}_{10} \mathrm{O}_{5}$ \\
\hline & $i$-Erythritol & $\mathrm{C}_{4} \mathrm{H}_{10} \mathrm{O}_{4}$ \\
\hline & $\begin{array}{l}N \text {-Acetyl-d-glucosamin } \\
\mathrm{e}\end{array}$ & $\mathrm{C}_{8} \mathrm{H}_{15} \mathrm{NO}_{6}$ \\
\hline \multirow{9}{*}{$\begin{array}{l}\text { Carboxylic } \\
\text { acids }\end{array}$} & $\gamma$-Hydroxy butyric acid & $\mathrm{C}_{4} \mathrm{H}_{8} \mathrm{O}_{3}$ \\
\hline & $\alpha$-Keto butyric acid & $\mathrm{C}_{4} \mathrm{H}_{6} \mathrm{O}_{3}$ \\
\hline & 2-Hydroxy benzoic acid & $\mathrm{C}_{7} \mathrm{H}_{6} \mathrm{O}_{3}$ \\
\hline & 4-Hydroxy benzoic acid & $\mathrm{C}_{7} \mathrm{H}_{6} \mathrm{O}_{3}$ \\
\hline & $\begin{array}{l}\text { d-Galactonic acid } \\
\gamma \text {-lactone }\end{array}$ & $\mathrm{C}_{6} \mathrm{H}_{10} \mathrm{O}_{6}$ \\
\hline & d-Galacturonic acid & C6H10O7 \\
\hline & d-Glucosaminic acid & C6H13NO6 \\
\hline & d-Malic acid & $\mathrm{C} 4 \mathrm{H} 6 \mathrm{O} 5$ \\
\hline & Itaconic acid & $\mathrm{C} 5 \mathrm{H} 6 \mathrm{O} 4$ \\
\hline \multirow[t]{3}{*}{ Miscellaneous } & $\begin{array}{l}\text { d,l- } \alpha \text {-Glycerol phos- } \\
\text { phate }\end{array}$ & $\mathrm{C} 3 \mathrm{H} 9 \mathrm{O} 6 \mathrm{P}$ \\
\hline & Glucose-1-phosphate & С6H13O9P \\
\hline & $\begin{array}{l}\text { Pyruvic acid methyl } \\
\text { ester }\end{array}$ & $\mathrm{C} 4 \mathrm{H} 6 \mathrm{O} 3$ \\
\hline \multirow[t]{4}{*}{ Polymers } & $\alpha$-Cyclodextrin & $\mathrm{C} 36 \mathrm{H} 60 \mathrm{O} 30$ \\
\hline & Glycogen & $(\mathrm{C} 6 \mathrm{H} 10 \mathrm{O} 5) \mathrm{n}$ \\
\hline & Tween 40 & \\
\hline & Tween 80 & \\
\hline
\end{tabular}

\section{APPLICATIONS OF BIOLOG ECOPLATES IN THE STUDIES OF SOIL MICROBIAL COM- MUNITIES}

Biolog Eco plates have been widely used in the studies of soil microbial communities which mainly included evaluating the effects on soil microorganism by different land-use type, fertilizers, contaminants, and so on. The 31 individual carbon sources on Biolog Eco plates, with a lot of ecological information, provide rich preference for analyzing the mechanism of some factors effecting on soil microorganism.

Liu el in [12] applied Biolog EcoPlates to assess soil community-level physiological profiles (CLPP) to the addition of chlortetracycline and found that CLPP responded rapidly to CTC-amendment and improved strongly by CTC on the first day, whereas no effect was detected thereafter, therefore the author believed that the Biolog EcoPlates method was more suitable for short-term toxicity tests than for the relatively long-term effects of pollutants on microbial communities. Zhang el in [13] used Eco plate to value the changes in Hulunbeier sandy land by different vegetation restoration patterns, the result that Caragana korshinskii treatment improved microbial metabolic activity and functional diversity greater than other treatments has been found. Chandra el in [14] tried to find changes in microbial functional diversity among different land-use types through Biolog Eco Plates, and the improvement of soil quality after the conversion from fallow grassland to organically cultivated field was due to the enhanced microbial functional diversity. Wang el in [15] studied the effects of fertilization on bacterial community structure and function in a black soil of Dehui region estimated by Biolog, and the use of chemical fertilizer mainly decreased the catabolic activity of the fast growth bacteria or eutrophic bacteria was suggested in result.

Besides, Biolog Eco plates also have been widely used for the studies of microbial communities from the other environment, such as sea, wastewater or the air el at [16-18].

\section{OPERATION PROCEDURE AND OPTIMIZA- TION OF BIOLOG ECOPLATE IN APPLICA- TIONS}

\subsection{Operation procedure and optimization}

There are main three steps in Biolog technique: first, soil samples collection and storage; second, the inoculation of soil leaching solution; third, plate cultivation for 7-10 days, reading data each 24 hours. Although the procedure is simple, yet the optimization is needed during each step due to the susceptibility of microbial communities.

First, soil samples collection and storage. Many factors would affect microbial communities from collection to inoculation, such as, the time of storage, the temperature of delivery, the oxygen condition of zip-lock bags and so on. So far, the study of effects on soil microbial communities by factors of time, temperature, oxygen condition during deliver is few. Besides, different soil types have different response to the factors. Therefore, it is difficult to make operation standards, however, in order to reduce the interference of unknown factors, portable fridge is needed during collection, and the inoculation process needed to finish within 2 days.

The second step is the inoculation of soil leaching solution. In order to reduce the interference of microbes from other environment, all of the tools during the inoculation need autoclaved sterilization. Measuring soil by steel ladle and burning the ladle after each 
measuring to avoid contamination between different samples. The next step is using sterilizing phosphate buffer or $0.1145 \mathrm{~mol} \mathrm{~L}^{-1} \mathrm{NaCl}$ solution to leach soil microorganism, however the sterilizing water could be used in the study of comparing the difference between different treatments [19-20]. Considering the effect of inoculation density, diluting 1000 times has been used normally. The time of transferring the liquor to the plates should be shortened within 5 minutes, or else the 3 replications in one plate would have difference due to time difference. Recently, our study showed that even though using the same liquor in 3 zones in plates, the difference between 1 zone and 3zone were observed due to the time difference of inoculation. Besides, the difference of 3 zones in principle component analysis (PCA) were observed, that the third zone is lower than the others in PC2 (Figure1).

Third step is culturing the microorganism from soil leaching solution in plate for 7-10 days, and reading the data in each 24 hours. During the process, normally, a fit temperature, 28-30 degree, should be required for culturing.

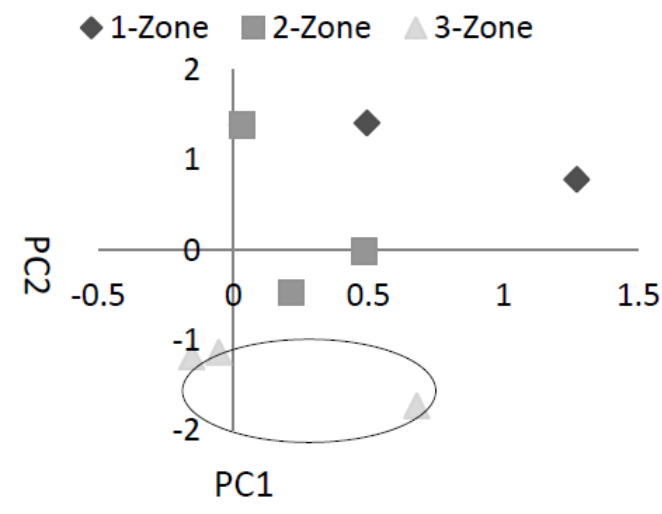

Figure 1. PCA result of 3 zones in Eco plate by using the same soil solution

\subsection{Optimization of data analysis}

Biolog Eco plates can provide huge data, therefore how to extract the information from the huge data in a rapid and effective way is the key to popularize this technology. Based on the color change in micro cores, there are mainly 2 aspects in the analysis of data: dynamic analysis and static analysis. Dynamic analysis can reflect the growth trend of microbes in 10 days by using average well color development (AWCD) each day (Figure2). The function of AWCD as follow:

$$
\begin{aligned}
& \mathrm{AWCD}=\sum\left(C_{i}-R\right) / 31 \\
& C_{i}: \text { The } \mathrm{OD}_{590 \mathrm{~nm}} \text { values in } 31 \text { carbon wells. } \\
& \mathrm{R} \text { : The } \mathrm{OD}_{590 \mathrm{~nm}} \text { value in control well. }
\end{aligned}
$$

Static analysis means use $\mathrm{OD}_{590 \mathrm{~nm}}$ value from one timing to analyze. However, its timing should be used has controversy, some studies showed the time of $72 \mathrm{~h}$ or $96 \mathrm{~h}$ is the more reasonable time since fungi will spread after 96h inoculation [21]. Jia el at [22] claimed that $144 \mathrm{~h}$ or $168 \mathrm{~h}$ is better, because the $\mathrm{OD}_{590 \mathrm{~nm}}$ value is still in fluctuation before that time. Consider the different conditions in different studies, in order to optimize the analysis result, the advice that selecting two time-points for analysis is suggested. Calculating the utilization of 6 kinds of carbon sources, Amines/amides, Amino acids, Carbohydrates, Carboxylic acids, Miscellaneous, Polymers, by different samples is a part of the content of static analysis, besides, calculating diversity index of carbon utilization and PCA based 31 carbons as variables are also included in static analysis. The functions of shannon diversity index, evenness index, simpson index, McIntosh index, McIntosh evenness as follow:

Shannon diversity index:

$$
\mathrm{H}^{\prime}=-\sum p_{i} \times\left(\ln p_{i}\right)
$$

\section{Shannon evenness index:}

$E=H^{\prime} / \ln S$

Simpson index:

$\mathrm{D}=\sum \frac{n_{i} \times\left(n_{i}-1\right)}{N \times(N-1)}$

McIntosh index:

$\mathrm{U}=\sqrt{\sum n_{i}^{2}}$

McIntosh evenness:

$\mathrm{E}=\frac{N-U}{N-N / \sqrt{S}}$

$p_{i}$ : The $\mathrm{OD}_{590 \mathrm{~nm}}$ value in $\mathrm{i}$ well divide mean

$\mathrm{OD}_{590 \mathrm{~nm}}$ value of 31 wells.

$S$ : The number of the wells ( 31 here).

$n_{i}$ : The relative $\mathrm{OD}_{590 \mathrm{~nm}}$ value in i well (C-R).

$\mathrm{N}$ : The sum of $\mathrm{OD}_{590 \mathrm{~nm}}$ value of 31 wells.

Most of Biolog data is extracted as the format of .xls, which means the authors get the original data in Excel context. Thousands useful functions in Excel, which help users to calculate the values in a convenient way. In this case, the use of two functions can achieve optimization in analysis. One of them is "absolute used", which is used when you need calculate relative $\mathrm{OD}_{590 \mathrm{~nm}}$ of 31 carbon wells (minus the value in control well). For example, the value of control core is in A2 blank, you want to use each other value to 


\section{MATEC Web of Conferences}

minus this value, you can use the value like this way: "\$A $\$ 2$ ", then you drag the mouse and copy the function in different files. When you analysis growth trend, you need to extract the AWCD value of each day, the functions of "INDIRECT" can be used in this case. First, put 10 days original data in 10 sheets belonged one file. Then you need put the value of AWCD in the same blank in each sheet, for exam "A20", the function "INDIRECT ("Sheet"\&ROW()-1\&"!\$A20")" was used in one blank in sheet11, then drag the mouse. In that way, you could get AWCD value of each day.

Because each carbon source is considered as one variable in analysis, in order to extract the information from the 31 variables in an effective way, more than $60 \%$ of studies applied PCA to reduce variables and reflect the difference in carbon sources utilization between different treatments. However, a lot of studies so far applied 2 PCs to extract information, which leads to low utilization of original data. In our recent study, the increase of principle components was an effective way to extract more information (Figure 3). Weber el at [23] found that through "Taylor" or "logic" transformation of original data before PCA, the similarity of variance, normal data and significant linear correlation data could be raised. Therefore, transformation of data forms in different cases is also an approach of optimization.

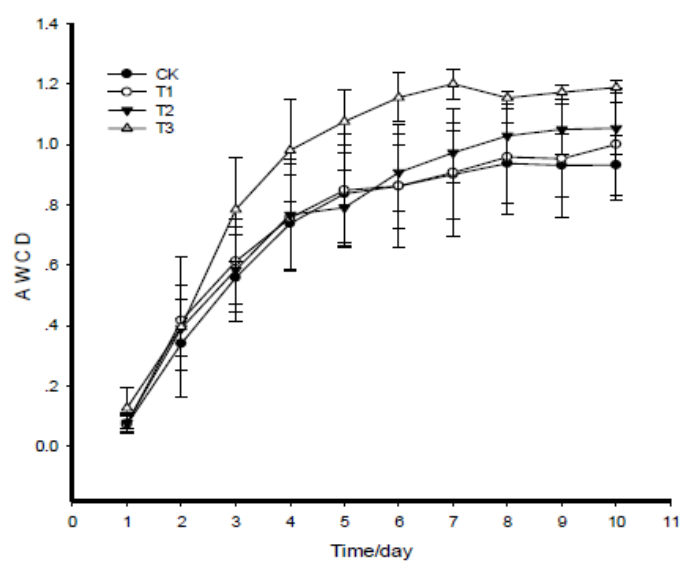

Figure 2. Development trend of AWCD in 10 days of soil samples in different treatments

\section{CONCLUSION}

Biolog Eco plates have been widely used in various areas due to its convenience, in spite of its obvious problems which are hard to solve in general. The main problems while applying the Eco plates are broadly summarized into three parts. (1) Most problems are related to operation procedure. So far, there is not standard operation procedure this technique, and some interference during the deliver and procedure can't be avoided. For example, the conditions in transfer and the pretreatment before inoculation could affect soil microbial communities or not? The density of microbes in solution can't prove to be even, therefore the result reflect the difference of microbial communities or density of microbes in fact? There are 3 replications in Eco plates, however whether the difference among 3 replications would bring difference in analysis or not? Besides, how much the dilution process would lead to the loss of weak microbial communities? (2) Some problems are related to cultivating process. Some researchers [24] claimed that the microbial communities would have changed during the culturing, therefore they believed that this method just reflect the carbon utilization by the most competitive communities in soil instead of all the communities in real environment. Other groups of researchers [25] found the color change in a well caused by microbial communities is different with the sum of color change caused by each single microbe, because antagonism or synergism in different kinds of microbes is remained to be found. Besides, due to evaporation, the culturing solution will reduce after 7-10 days, so whether the loss of solution will cause the difference or not in result is uncertain. (3) The problems of data analysis. As to data analysis, the biggest controversy is that timing is best for analysis. Some studies showed the value in 72-hour or 96-hour is the more reasonable time since fungi will spread after $96 \mathrm{~h}$ inoculation, while Jia el in [22] claimed that 144-hour or 168-hour is better, because the $\mathrm{OD}_{590 \mathrm{~nm}}$ value is still in fluctuation before that time. Whether the diversity index could explain the functional diversity of microbes or not is also a controversy, besides, classification on 31 carbon sources caused different opinions, some researchers [26] classify them into 6 groups: amines/amides, amino acids, carbohydrates, carboxylic acids, miscellaneous, polymers, while others [27] divide them into 4 groups: sugar and its derivative, amino acids and its derivative, fatty acid and lipids, metabolic mediates and secondary metabolites.

Despite of having some problems while applying Biolog Eco plates, it has a numbers of prospects in the field of microbial communities research as it provides rich information and reflects the metabolic status of microbes. They also provide assessment criteria for the quality and ecological security of soil, and provide reference for optimizing microbial construction. Microbial constructions are present in virtually all environments and typically the first organism to react to chemical and physical changes in the environment. Because, they are the bottom of the food chain, changes in microbial communities are often a precursor to changes in the health and vitality of the environment as a whole.

So, while working with Biolog Eco plates, basically three advises were suggested for improvement of the result and minimize the bias occurred during the process:: (1) Build up a standard operation procedures Specifically, basic experiment studies should be increased, such as how storage and pretreatments affect the result, so that accessible and accurate operation procedure could be built up and the results from dif- 
ICETA 2015

ferent studies become comparable. (2) Popularize and optimize data analysis. So far, due to the complexity of data analysis, a lot of studies analyzed the data superficially, such as, only use AWCD to analyze, which caused large waste. Many methods used in Biolog data analysis [28]. Besides PCA and clustering analysis, the numbers of methods are in practice for analyzing the data major of which includes: Self-Organization Mapping net (SOM), Most Probable Number (MPN), Lorenz curve or Gini coefficient. So training or lecturing should be suggested, so that those methods could be used popularly among researchers. (3) Build the coordination between different subjects. The controversy about classification of carbon sources could be settled by making appropriate coordination between ecology and microbiology researchers. Some ecology researchers have the lack of the knowledge and biological information behind 31 carbon sources, so they shallowly analyzed that how much the carbon has been used, which lead to the loss of message. If these aspects could attach more importance and be developed, Biolog Eco plates would have a wider space in various areas, meanwhile, it would be as an effective and rapid method to reflect the functional diversity and metabolic ability of microbial communities.
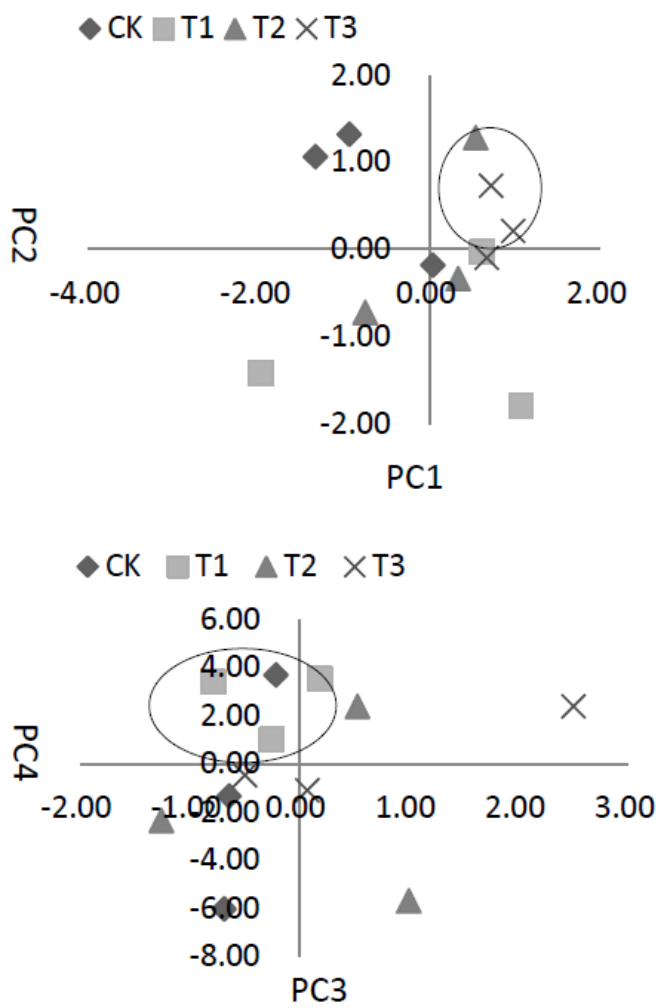

Figure 3. PCA of soil samples in different treatments after the increase of PCs

\section{ACKNOWLEDGEMENT}

This paper is sponsored by National Basic Research Program of China (973 Program, N o. 2012CB416904) and Priority Academic Program D evelopment of Jiangsu Higher Education Institutions (PAPD).

\section{REFERENCES}

[1] McNaughton S. J. 1977. Diversity and stability of ecological communities: a comment on the role of empiricism in ecology. American Naturalist, 515-525.

[2] Tilman D. et al. 1998. Diversity - Stability Relationships: Statistical Inevitability or Ecological Consequence? The American Naturalist, 151 (3): 277-282.

[3] Gross K. et al. 2014. Species Richness and the Temporal Stability of Biomass Production: A New Analysis of Recent Biodiversity Experiments. The American Naturalist, 183(1): 1-12.

[4] Rao, N. S. S. 1995. Soil microorganisms and plant growth (No. Ed. 3). Science Publishers, Inc.

[5] Singh J. S. et al. 2011. Efficient soil microorganisms: a new dimension for sustainable agriculture and environmental development. Agriculture, ecosystems \& environment, 140(3): 339-353.

[6] Lau J. A. \& Lennon J. T. 2012. Rapid responses of soil microorganisms improve plant fitness in novel environments. Proceedings of the National Academy of Sciences, 109(35): 14058-14062.

[7] Campbell C. D. et al. 1997. Use of rhizosphere carbon sources in sole carbon source tests to discriminate soil microbial communities. Journal of Microbiological Methods, 30(1): 33-41.

[8] Van Elsas J. D. et al. 2012. Microbial diversity determines the invasion of soil by a bacterial pathogen. Proceedings of the National Academy of Sciences, 109(4): 1159-1164.

[9] Rastogi G. \& Sani R K. 2011. Molecular techniques to assess microbial community structure, function, and dynamics in the environment, Microbes and Microbial Technology. Springer New York, 29-57.

[10] Smit E. et al. 2001. Diversity and seasonal fluctuations of the dominant members of the bacterial soil community in a wheat field as determined by cultivation and molecular methods. Applied and Environmental Microbiology, 67(5): 2284-2291.

[11] Widmer F. et al. 2001. Assessing soil biological characteristics: a comparison of bulk soil community DNA-, PLFA-, and Biolog ${ }^{\mathrm{TM}}-$ analyses. Soil Biology and Biochemistry, 33(7): 1029-1036.

[12]Liu B. et al. 2015. Effects of chlortetracycline on soil microbial communities: Comparisons of enzyme activities to the functional diversity via Biolog EcoPlates ${ }^{\mathrm{TM}}$, European Journal of Soil Biology, http://dx.doi.org/10.1016/j.ejsobi.2015.01.002

[13]Zhang H. et al. 2013. Changes in soil microbial functional diversity under different vegetation restoration patterns for Hulunbeier Sandy Land. Acta Ecologica Sinica, 33(1): 38-44. 


\section{MATEC Web of Conferences}

[14]Nautiyal C. S. 2010. Chauhan P S, Bhatia C R. Changes in soil physicochemical properties and microbial functional diversity due to 14 years of conversion of grassland to organic agriculture in semi-arid agro ecosystem. Soil and Tillage Research, 109(2): 55-60.

[15]Guanghua W. et al. 2008. Effects of fertilization on bacterial community structure and function in a black soil of Dehui region estimated by Biolog and PCR-DGGE methods. Acta Ecologica Sinica, 28(1) 220-226.

[16]Deng J. et al. 2014. Stability, genotypic and phenotypic diversity of Shewanella baltica in the redox transition zone of the Baltic Sea. Environmental microbiology, 16(6): 1854-1866

[17]Zhang T. Y. et al. 2014 Screening heterotrophic microalgal strains by using the Biolog method for biofuel production from organic wastewater. J. Algal Research, 6: $175-179$.

[18]Ling Q. et al. 2012. Analysis of Carbon Metabolism Diversity Characters of Air Microbes in Huangshan Scenic Spot Using Biolog-Eco Method. Journal of Basic Science and Engineering, 1: 008.

[19]Schutter M. \& Dick R. 2001. Shifts in substrate utilization potential and structure of soil microbial communities in response to carbon substrates. Soil Biology and Biochemistry, 33(11): 1481-1491.

[20]Bååth E. et al. 1998. Effect of metal-rich sludge amendments on the soil microbial community. Applied and environmental Microbiology, 64(1): 238-245.

[21] Cai Y. F. et al. 2010. Soil bacterial functional diversity is associated with the decline of Eucalyptus gomphocephala. Forest Ecology and Management, 260(6): 1047-1057.

[22]Jia X. et al. 2013. Effects of Biolog Eco-plates Incubation Time on Analysis Results in Microbial Ecology Researches. Journal of Basic Science and Engineering, 01:10-19.

[23] Weber K. P. et al. 2007. Data transformations in the analysis of community-level substrate utilization data from microplates. Journal of microbiological methods, 69(3): 461-469.

[24] Smalla K. et al. 1998. Analysis of BIOLOG GN substrate utilization patterns by microbial communities. Applied and Environmental Microbiology, 64(4): 1220-1225

[25]Haack S. K. et al. 1995. Analysis of factors affecting the accuracy, reproducibility, and interpretation of microbial community carbon source utilization patterns, J. Applied and Environmental Microbiology, 61(4): 1458-1468.

[26] Yang Y. et al. 2009. Influences of Bacillus on metabolic functions of microbial communities in fishponds. Journal of Microbiology, 3: 003 .

[27]Zhang Y. Y. et al. 2009. An amendment on information extraction of Biolog EcoPlateTM. Microbiology, 36(7): 1083-1091

[28]Tian Y. N. \& Wang H. Q. 2011. Application of Biolog to study of environmental microbial function diversity. Environmental Science Technology, 34(3): 50-57. 